\title{
OFICINA ALQUIMIA: INTEGRANDO INTELECTO E EMOÇÃO NAS ALTAS HABILIDADES ${ }^{31}$ \\ ALQUIMIA OFFICE: INTEGRATING INTELLECT AND EMOTION IN HIGH SKILLS
}

Inês Raquel Zaniboni Guzzo 32

Lucia de Mello e Souza Lehmann ${ }^{33}$

\begin{abstract}
RESUMO
Este artigo apresenta uma oficina realizada com um grupo de doze adolescentes com Altas Habilidades ou Superdotação (AH/SD) no Curso de Verão, indicados pela Escola de Inclusão da Universidade Federal Fluminense. O objetivo do trabalho foi conhecer e elaborar com os adolescentes como pensam, se relacionam e manifestam as emoções, valorizando a importância da integralidade dos aspectos emocionais e intelectuais. Fundamenta-se no tema das AH/SD estabelecido no âmbito da Educação Especial e no conceito de Projeção. A oficina utilizou como método a pesquisa-ação. Os resultados demonstram que os aspectos cognitivos presentes na superdotação são atravessados pelos afetos e emoções e esta dinâmica tem uma presença determinante na vida cotidiana, no desempenho e na escolha feita por estes jovens.
\end{abstract}

Palavras-chave: Adolescentes. Altas habilidades ou superdotação. Afetos.

\section{ABSTRACT}

This article presents a workshop conducted with a group of twelve adolescents with High Skills or Giftedness (AH / SD) in the Summer Course indicated by the Inclusion School of the Fluminense Federal University. The objective of the work was to know and elaborate the adolescents as they think, relate and manifest themselves as emotions, valuing the importance of the integrality of emotional and intellectual aspects. It is based on the theme AH / SD established within the scope of Special Education and the concept of Projection. The workshop used as an action research method. The results show which cognitive aspects are present in giftedness and are crossed by effects and emotions, and that this presence has a determining presence in daily life, without performance and in the choice made by these young people.

Keywords: Adolescents. High skills or giftedness. Affects.

\footnotetext{
31 Parte desse texto foi apresentado em formato de Pôster no I Congresso Brasileiro de Educação de Superdotados e publicado nos Anais do Congresso.

32 Psicóloga e Mestre em Diversidade e Inclusão- CMPDI - UFF; E-mail: $\underline{\text { raquelguzzo@yahoo.com.br }}$

${ }^{33}$ Professora Doutora/prof. do Curso de Mestrado Profissional em Diversidade e Inclusão - CMPDI - UFF e do PPG Doutorado em Ciência, Tecnologia e Inclusão E-mail: lehmannlucia@gmail.com
} 


\section{RevistAleph}

\section{Introdução}

A Política Nacional de Educação Especial na Perspectiva da Educação Inclusiva publicada em 2008 definiu os alunos atendidos por esta modalidade educativa, dentre estes os superdotados, que assim são definidos:

Estudantes com altas habilidades/superdotação demonstram potencial elevado em qualquer uma das seguintes áreas, isoladas ou combinadas: intelectual, acadêmica, liderança, psicomotricidade e artes, além de apresentar grande criatividade, envolvimento na aprendizagem e realização de tarefas em áreas de seu interesse.

Em 2011 o termo passou a ser Altas Habilidades ou Superdotação “[...]deixando clara a intenção do legislador quanto à sinonímia legal dos termos" (CARDOSO, 2016, p. 14).

Usualmente, o aspecto intelectual é evidenciado e ressaltado nos indivíduos com Altas Habilidades ou Superdotação (AH/SD), principalmente no que se refere ao âmbito escolar e educacional. Características emocionais e de personalidade ficam em segundo plano. Será que isto realmente se confirma? Contudo são extremamente importantes na dinâmica dos jovens, dando direcionamento mais proveitoso ou mesmo prejudicando o desempenho e a realização de potenciais.

Segundo Landau (1990), o desenvolvimento do superdotado deve ser integral, ou seja, os aspectos intelectual e emocional da personalidade merecem igual atenção, uma vez que, uma estimulação que privilegie somente o aspecto cognitivo deixa a deriva aspectos que favorecem o desenvolvimento da maturidade emocional, enquanto o contrário, onde só o emocional é estimulado, poderá resultar em uma frustração cognitiva. A autora chama atenção para a relevante integração desses dois aspectos, que são imbricados na revelação e no avanço das potencialidades da criança superdotada. Assim, Landau (1990, p. 69) salienta:

Uma indicação exclusivamente cognitiva levará eventualmente ao desenvolvimento intelectual, contudo poderá fazer com que a criança permanece emocionalmente imatura. Ao passo que a estimulação emocional, sem a cognitiva, conduzirá à frustração intelectual. Em ambos os casos, a criança superdotada não atualizará seus potenciais. Somente com a interação entre um ambiente que promova desafios 


\section{RevistAleph}

emocionais e intelectuais e as capacidades da criança, a atualização da superdotação será real.

A influência das emoções, também são evidenciadas por Robert Sternberg, enfatizando que "pessoas com inteligência de sucesso aprendem a controlar seus impulsos" (STERNBERG, 2000, p. 218). O autor sustenta que em determinados períodos da vida, o comportamento impulsivo, pode até se tornar inevitável e necessário, entretanto, seu curso tende a prejudicar o trabalho intelectual. Sternberg (2000) aponta que, apesar dos professores observarem excelentes capacidades em alguns alunos, estes em grande parte, não conseguem demonstrar seus potenciais, pois em muitas situações, não controlam a impulsividade e a tendência de agirem sem reflexão.

Segundo Ourofino \& Guimarães (2007) há um descompasso entre o desenvolvimento afetivo, cognitivo e psicomotor nos indivíduos com altas habilidades ou superdotação em relação aos seus pares. As autoras atribuem esse fato ao modo particular dessas pessoas, que são notados pela grande sensibilidade resultante de um acúmulo maior de informações e emoções. Estas consideram que o desenvolvimento emocional do superdotado é oriundo de alta capacidade e de percepção aguçada e que para a compreensão de suas emoções a pessoa com altas habilidades ou superdotação despende alto nível de energia psíquica, um esforço que pode estar além de sua idade cronológica.

Buscando explorar e trabalhar a compreensão das experiências afetivas e emoções dos jovens identificados com AH/SD foi criada a oficina Alquimia oferecida no Curso de Verão da Universidade Federal Fluminense. O objetivo foi criar um ambiente visando conhecer a dinâmica dos alunos permitindo-os "aplicar suas habilidades verbais e de compreensão avançadas às suas experiências afetivas" (OUROFINO \& GUIMARÃES, 2007, p. 48).

Antes de entrar no contexto de desenvolvimento da oficina e da metodologia do trabalho cabe explicar alguns fundamentos que nortearam as atividades.

O espaço e a dinâmica identificados como oficina, foram utilizados para o estímulo à troca e reflexão de experiências. Segundo Candau (1999, p. 11): 


\section{RevistAleph}

As oficinas são espaços de construção coletiva de um saber, de análise da realidade, de confrontação e intercâmbio de experiências, de exercício concreto dos direitos humanos. A atividade, a participação, a socialização da palavra, a vivência de situações concretas através de sóciodramas, a análise de acontecimentos, a leitura e discussão de textos, a realização de vídeodebates, o trabalho com diferentes expressões da cultura popular, etc, são elementos presentes na dinâmica das oficinas.

A atividade da oficina coloca em evidencia atitudes e falas, além de se levar em conta o conteúdo manifesto do que é dito, é possível buscar um maior entendimento dos conteúdos latentes, atitudes, escolhas, através da compreensão do mecanismo de projeção.

Quando um escritor produz um texto ou um artista pinta uma obra podemos ver ali traços e características daquele artista e muitas vezes a obra é tão expressiva, que somos capazes de perceber o sentimento do artista. Chamamos a esta dinâmica de Projeção.

Projeção é o termo utilizado para representar um mecanismo presente nas relações humanas elaborado mais precisamente, na Psicologia e na psicanálise, para explicar o recurso pelo qual o sujeito coloca no objeto ou em uma relação o que internamente está sentindo ou pensando.

Na psicanálise o termo projeção se refere tanto a padrões normais como patológicos e é definido por Laplanche \& Pontalis (1992, p. 379)

“a) Num sentido comparável ao sentido cinematográfico: o sujeito envia para fora a imagem do que existe de forma inconsciente. Aqui a projeção define-se como um modo de desconhecimento, tendo como contrapartida o conhecimento em outrem daquilo que, precisamente, o sujeito desconhece em si mesmo;

b) Como um processo de expulsão quase real: o sujeito lança para fora de si aquilo que não quer e o encontra a seguir no mundo exterior. Aqui, poderíamos dizer esquematicamente que a projeção não se define como "não querer conhecer", mas como "não querer se".'

O termo projeção também é compreendido como um mecanismo no qual o sujeito percebe e responde aos estímulos do ambiente de acordo com seus interesses, aptidões, hábitos, expectativas e estados afetivos mostrando através de suas atitudes 


\section{RevistAleph}

que "assimila-se a pessoas estranhas ou, inversamente, assimila a si mesmo pessoas, seres animados ou inanimados" (PONTALIS \& LANPLANCHE, 1992, 375).

\section{A Oficina Alquimia em seu contexto: o Curso de Verão para Superdotados}

A oficina Alquimia desenvolvida com adolescentes ocorreu em 2018 uma edição do Curso para Superdotados, tendo duas horas de duração. O curso é organizado em duas edições que acontecem no inverno e no verão.

A primeira versão do Curso de Verão para Superdotados da Universidade Fluminense aconteceu em janeiro de 2013, resultado da criação da Rede de Interações, assim definida por Cardoso (2016, p. 32-35):

[...] uma Rede de Interações que atenda os indivíduos com altas habilidades ou vocações científicas para área da Biotecnologia foi organizada tendo como principais atores:

1. Universidade: A universidade tem papel central em uma sociedade contemporânea onde o conhecimento é a base de muitas relações e processos [...].

2. Empresa: [...] ao ampliarem parcerias com a comunidade escolar em seu entorno oportunizam o aprendizado e o crescimento pessoal e profissional dos alunos, atuando na formação de futuros pesquisadores para a área das Ciências.

3. Escola: considerada local de convergência de culturas - religiosa, política, e conhecimento - onde normas são estabelecidas, muitas vezes buscando práticas de transmissão de conhecimentos [...].

Em sua primeira versão, buscou-se atender às demandas advindas do I Encontro de Crianças e Jovens Superdotados do Rio de Janeiro promovido pelo Conselho Brasileiro de Superdotação (ConBraSD) e do ISMART (Instituto Social para Motivar, Apoiar e Reconhecer Talentos) (CARDOSO, 2016, p. 80).

Atualmente o Curso de Verão está vinculado ao Programa de Extensão da Escola de Inclusão, responsável pela avaliação e encaminhamento de crianças e adolescentes com altas habilidades ou superdotação e com o Curso de Mestrado em Diversidade e Inclusão do Instituto de Biologia da Universidade Federal Fluminense, situado no município de Niterói do estado do Rio de Janeiro. 


\section{RevistAleph}

O Curso de Verão no qual foi realizada a Oficina Alquimia contou com a duração de 5 dias, de segunda-feira a sexta-feira, sendo as oficinas realizadas em período vespertino, entre $13 \mathrm{~h}$ às $17 \mathrm{~h}$, com um intervalo para o lanche. Neste intervalo, foi organizado o Corredor Pedagógico, um espaço dedicado a materiais e jogos para experiências de forma lúdica para os participantes das oficinas. Momento de interação e diversão os adolescentes e seus familiares.

\section{Metodologia}

O trabalho baseou-se na pesquisa-ação, na medida em que esta metodologia possibilita uma forma de planejamento na qual se considera a importância, não só da participação e da ação, como também das discussões para a produção de conhecimento e aquisição de novas experiências sobre as questões abordadas (THIOLLENT, 1985).

Nesse sentido, a oficina visou a construção de um espaço de reflexão dialógica, com a participação coletiva, suscitada pelo o debate das questões apresentadas nas atividades desenvolvidas.

\section{Materiais}

Foram utilizadas figuras de animais, baseadas nos folclores dos índios norteamericanos, do livro: "Tarô dos índios". Este instrumento foi utilizado porque favorece mecanismos de projeção, como explicitado anteriormente no texto, e a identificação, em que o sujeito se vê, sente-se representado nas figuras apresentadas e o Jogo Túnel do Tempo. O jogo é composto de um tabuleiro, um dado, um pino e de 165 cartas para serem respondidas individualmente, assim distribuídas: Passado (45 cartas); Presente (70 cartas); Futuro (14 cartas); Você no futuro (09); Casos e acasos (17 cartas); Falando de .... " Só para meninas"(04 cartas) e Falando de ...... " Só para meninos" (06 cartas). 0 objetivo do jogo é oferecer aos adolescentes, possibilidades de reflexões acerca de sua vida - fatos passados, atuais e imaginar o futuro - promovendo situações para o autoconhecimento. 


\section{RevistAleph}

O jogo começa com um participante jogando o dado, e colocando o pino na casa indicada. Apresenta a possibilidade de duas saídas uma pela direita e outra pela esquerda, e termina com o fim das cartas, sendo assim, não tendo vencedores.

Métodos: Foi feita uma seleção preliminar das cartas do jogo Túnel do Tempo, por considerar as características do grupo: diferença de idades, maioria do sexo masculino e a brevidade do encontro. Nesta seleção, não foram utilizadas 39 (trinta e nove), sendo relativas aos itens: Passado - 15 (quinze), Presente - 6 (seis), Futuro - 4 (quatro), Casos e Acasos - 7 (sete), Você no Futuro - 8 (oito), Falando de meninas - 3 (três).

\section{Descrição das atividades}

A oficina foi iniciada com a solicitação para que os adolescentes escolhessem uma carta com as figuras de animais, relacionados ao folclore dos índios norteamericanos, que estavam expostas em uma mesa. Cada um pegou a figura do animal que mais se identificou, gostava, achava alguma característica que poderia se assemelhar às suas próprias. Após esse momento, os participantes foram organizados em círculo em torno de uma mesa e convidados a participarem do jogo Túnel do Tempo.

Com o término do jogo foi realizada a leitura do significado das cartas das figuras dos animais, com a finalidade de apresentar a cada um a palavra que representava o animal da carta que foi escolhida no início da oficina, sendo enfatizado o significado positivo de cada palavra. Baseado no conceito de projeção, verifica-se neste momento do trabalho, a relação entre o conteúdo manifesto e o conteúdo latente provocado por esta dinâmica.

Ao final da oficina foi realizada uma avaliação, contendo quatro itens: 1 . Acho importante conhecer minhas emoções; 2 . Acho importante conhecer as emoções dos outros; 3. Gosto de ouvir o que os outros falam; 4. Aprendi coisas novas na oficina. Estes itens foram avaliados através de três critérios: concordo; concordo parcialmente; discordo. 


\section{RevistAleph}

\section{Resultados e Discussão}

O comportamento expresso pelos adolescentes, brincadeiras, risadas e falatório foi acompanhado de uma maioria interessada e participante no desenvolvimento da oficina, excetuando dois adolescentes que riram e "ironizaram" durante a maior parte do tempo, necessitando, inclusive de intervenções constantes.

Este comportamento pode estar relacionado a uma conduta da pré-tarefa que se refere a uma atitude de resistência, na qual o indivíduo evita de modo ansioso a mudança de comportamento, o que dificulta assumir a tarefa, sendo esta compreendida como "[...]um organizador dos processos de pensamento, de comunicação e de ação do que está sendo vivenciado[...] (WEISS, 2015, p.14).

Nenhum adolescente se recusou a participar das atividades propostas. Imersos em um clima afetivo do grupo, que por vezes tornava-se barulhento, todos responderam e refletiram sobre as questões do jogo, cada um com seu estilo, uns mais reflexivos, outros mais evasivos e impulsivos.

Alguns adolescentes se mostraram intrigados em relação ao final do jogo, pois perceberam que só tinha saída e não chegada, sendo assim, não haveria ganhadores, porém, esta constatação não diminuiu o interesse pelo jogo.

A seleção preliminar das cartas foi de grande valia para a dinâmica do jogo, uma vez que as cartas selecionadas estavam diretamente focadas no objetivo da oficina e a interação do grupo.

O número de participantes foi um fator que trouxe alguma dificuldade, pois a vez de cada um jogar novamente, ficou demorada e os colegas pressionavam para que as respostas fossem dadas e o jogo prosseguisse, bem ao ritmo dos jovens acelerados e nem sempre pacientes. Todavia, a dinâmica que os jovens impuseram ao jogo não inviabilizou reflexões, que foram beneficiadas pela atmosfera lúdica e divertida, já que conteúdos com importantes cargas emocionais foram evocados.

A avaliação da oficina realizada pelos adolescentes, evidenciou um feedback positivo em relação ao trabalho desenvolvido. O Quadro 1 retrata a participação e análise de todos nos itens avaliados. 


\section{RevistAleph}

Quadro 1. Avaliação da Oficina

\begin{tabular}{|c|c|c|c|}
\hline Itens avaliados & Concordo & $\begin{array}{l}\text { Concordo } \\
\text { parcialmente }\end{array}$ & Discordo \\
\hline $\begin{array}{l}\text { 1. Acho importante conhecer } \\
\text { minhas emoções. }\end{array}$ & $50 \%$ & $33 \%$ & $17 \%$ \\
\hline $\begin{array}{l}\text { 2. Acho importante conhecer as } \\
\text { emoções dos outros. }\end{array}$ & $42 \%$ & $42 \%$ & $17 \%$ \\
\hline $\begin{array}{l}\text { 3. Gosto de ouvir o que os } \\
\text { outros falam. }\end{array}$ & $58 \%$ & $25 \%$ & $17 \%$ \\
\hline $\begin{array}{l}\text { 4. Aprendi coisas novas na } \\
\text { oficina. }\end{array}$ & $67 \%$ & $25 \%$ & $8 \%$ \\
\hline
\end{tabular}

Fonte: A pesquisa

Pode ser observado na avaliação final que a metade dos participantes marcou o critério "concordo" no item 1, relativo a importância de conhecer as emoções, o que demonstra consideração em relação aos aspectos subjetivos.

Já o item 2, conhecer as emoções dos outros, apresenta o mesmo percentual (42\%) nos critérios "concordo" e "concordo parcialmente", o que pode evidenciar o interesse do adolescente, principalmente, e em primeiro lugar, por seus próprios sentimentos, o que não deixa de ser esperado neste momento da vida, uma vez que a referência a si próprio e o altruísmo ainda não estão construídos.

O critério "discordo" que mostra o mesmo resultado nos itens 1, 2 e 3, relativo ao conhecimento das emoções, denota que uma minoria não concordou com a importância de falar e reconhecer as emoções.

Estes posicionamentos demonstram o quanto a oficina ofereceu uma liberdade de participação e expressão, permitindo que os adolescentes se posicionassem livremente.

Como hipótese podemos dizer que o item "discordo" poderia ser tomado como uma defesa, no entanto não temos dados que permitam comprovar esta hipótese no momento, dado a limitação da investigação. 


\section{RevistAleph}

Cabe reconhecer também, que os sujeitos podem ter a liberdade de não querer ter maiores relacionamentos ou não terem curiosidade sobre os sentimentos próprios ou alheios, revelando uma atitude mais fechada diante das relações interpessoais.

Verifica-se que a maioria dos adolescentes (67\%) respondeu "concordo" no item 4, o que evidencia o interesse que tiveram pela oficina, ou seja, a oficina foi uma atividade bem acatada e que, portanto, foi tomada como positiva. Para os pesquisadores isto é um retorno importante porque demonstra que é uma estratégia que pode e deve ser utilizada na continuidade de trabalhos.

\section{Conclusão}

Os resultados demonstram que os aspectos presentes na superdotação são atravessados pelos afetos e emoções, e que esta dinâmica tem uma presença determinante na vida cotidiana, no desempenho e na escolha feita por estes jovens.

A oficina possibilitou aos adolescentes uma experiência de expressão de fala, de manifestação de atitudes e pensamentos de modo lúdico e interativo, ao mesmo tempo, em que estimulou a escuta ativa possibilitando o conhecimento da história de vida dos colegas, bem como opiniões e desejos de cada um.

O jogo demonstrou ser um instrumento eficaz para auxiliar os adolescentes com $\mathrm{AH} / \mathrm{SD}$ a refletirem sobre situações concretas e hipotéticas da vida. A escolha das cartas e a leitura das palavras que representa cada animal ilustrados nas cartas, oportunizou aos adolescentes, por meio do mecanismo de projeção, uma experiência, de modo lúdico e jocoso a entrarem em contato com certos traços de personalidade.

A experiência aponta para os pesquisadores e, os que desejam trabalhar com esses grupos, que novos arranjos podem favorecer uma atmosfera mais interativa, no que se refere ao jogo Túnel do Tempo com os adolescentes com AH/SD. Dentre estes arranjos, pode-se sugerir que os participantes respondam a uma única carta em cada rodada de dados. Espera-se, desse modo, estimular respostas de construção coletiva para uma determinada questão apresentada pelas cartas, favorecendo vínculos mais fraternos e de maior empatia. 


\section{RevistAleph}

Outro aspecto dessa experiência diz respeito ao número de participantes. Pode-se inferir que um grupo menor, provavelmente, facilitaria o processo de reflexão provocado pelas cartas do jogo, pois que haveria um maior tempo disponível para que cada participante pudesse aprofundar nas questões suscitadas por essa atividade.

Entre os focos trabalhados na oficina, destacam-se as demandas e conflitos consigo mesmo e no contato com os outros, vivenciados pelos adolescentes nos diversos espaços de circulação, e as experiências satisfatórias e de crescimento.

Cabe ainda evidenciar a relevância e o caráter paradoxal dos aspectos afetivos na dinâmica psíquica dos jovens, pois eles podem dar um direcionamento mais proveitoso ou ser prejudicial ao desempenho e a realização de potenciais.

A proposta apresentada nesta oficina se mostrou valiosa pelo uso de recursos dinâmicos que podem enriquecer o atendimento aos aspectos emocionais das pessoas com altas habilidades ou superdotação.

\section{Referências}

ARENALES-LOLI, M.S. Túnel do tempo: um jogo lúdico auxiliar no processo interativo entre profissionais e adolescentes/pré-adolescentes - 1aed. Assis/SP: Triunfal Gráfica e Editora, 2011.

BRASIL. Política Nacional de Educação Especial na Perspectiva da Educação Inclusiva. Brasília - Janeiro de 2008 ...[PDF] Portal do MEC. Disponível em: portal.mec.gov.br/arquivos/pdf/politicaeducespecial.pdf. Acesso em 07/02/2018

CANDAU, V.M. Oficinas Aprendendo e Ensinando Direitos Humanos - EDUCAÇÃO EM DIREITOS HUMANOS: UMA PROPOSTA DE TRABALHO. Novameria/PUC-Rio-1999. Disponível em:http://www.dhnet.org.br/direitos/militantes/veracandau/candau edh proposta trabalho .pdf. Acesso: 08/03/2018.

CARDOSO, F. S. Rede de interações como possibilidade para o desenvolvimento de pessoas com altas habilidades e vocações na área de biotecnologia / Fernanda Serpa Cardoso. Niterói: [s.n.], 2016. 272f. Tese (Doutorado em Ciências e Biotecnologia) - Universidade Federal Fluminense, 2016.

LANDAU, E. A coragem de ser superdotado. Tradução Sandra Miessa; revisão técnica Gohara Yvettte Yehia, Marília Ancora - Lopez, São Paulo; CERED, 1990.

LAPLANCHE, J. Vocabulário da Psicanálise. sob a direção de Daniel Lagache; [tradução Pedro Tamen].- 2a ed. São Paulo: Martins Fontes. 1992, p. 374-375.

MARTINEZ, V. Tarô dos Índios - As Cartas Totêmicas. Madras Editora Ltda. São Paulo, 1998. 


\section{RevistAleph}

OUROFINO, V.T.A.T.; GUIMARÃES, T.G. Características intelectuais, emocionais e sociais do aluno com altas habilidades/superdotação. In: FLEITH, D.S. (Org.). A construção de práticas educacionais para alunos com altas habilidades/superdotação. Brasília: Secretaria de Educação Especial, Ministério da Educação, 2007. v. 1, p. 43-51.

http://portal.mec.gov.br/images/revista_inclusao/altashab2.txt. Acesso em: 20/12/2017.

STERNBERG, J. R.A inteligência para o sucesso pessoal: como a inteligência prática e criativa determina o sucesso. Tradução de Caetano Manuel Filgueira Pimentel. Rio de Janeiro: Campus: 2000. 254 p.

THIOLLENT, M. Metodologia da pesquisa-ação / Michel Thiollent. - São Paulo : Cortez : Autores Associados, 1986. (Coleção temas básicos de pesquisa-ação).

WEISS, L. L. Maria. Intervenção psicopedagógica nas dificuldades de aprendizagem escolar. Coordenação de Alba Weiss. Rio de Janeiro: Wak Editora, 2015. 168p. : 21 cm.

Data do envio: 02/02/2019

Data do aceite: $12 / 12 / 2018$. 